\title{
Drogadição e Atos Infracionais na Voz do Adolescente em Conflito com a Lei
}

\author{
Sandra Eni Fernandes Nunes Pereira ${ }^{1}$ \\ Maria Fátima Olivier Sudbrack \\ Universidade de Brasília
}

\begin{abstract}
RESUMO - Por meio das abordagens sistêmica e psicossocial, o presente estudo tem como objetivo descrever e discutir a relação entre os níveis de dependência relacional das drogas e a prática de atos infracionais entre os jovens, na perspectiva do adolescente em conflito com a lei. As informações foram coletadas por entrevistas semi-estruturadas, aplicadas em 29 adolescentes, autores de infração, da Vara da Infância e Juventude de Brasília. O método de análise refere-se à análise de conteúdo do tipo construtivo-interpretativo. Os resultados apontam várias conexões entre os níveis de dependência relacional das drogas (efeitos, crenças, relações afetivas, pares, provedores, fornecedores) e a prática de infrações. Os diferentes níveis de dependência identificados na voz dos adolescentes mostram a multiplicidade e complexidade das relações entre a drogadição e a prática de atos infracionais entre jovens e, portanto, a necessidade de um trabalho de intervenção em rede.
\end{abstract}

Palavras-chave: adolescente; drogadição; atos infracionais; redes sociais.

\section{Drug Addiction and Infractional Acts in the Adolescent's Voice in Conflict with Law}

\begin{abstract}
Through systemic and psychosocial approaches, this study has the objective to describe and discuss the relation among the levels of relationary dependence of drugs and the practice of infractional acts among the youngsters, in the perspective of the adolescent in conflict with law. The information had been collected through half-structuralized interviews, applied to 29 adolescents, authors of infraction, from the Infancy and Youth Jurisdiction of Brasilia. The analysis method refers to the content analysis of the constructive-interpretative type. The results point to many connections among the levels of relationary dependence of drugs (effects, beliefs, affective relations, peers, purveyors and suppliers) and the practice of infractions. The different identified levels of dependence in the adolescents' voice show the multiplicity and complexity of the relations between drug addiction and the practice of infractional acts among youngsters and, therefore, the necessity of a work intervention in net.
\end{abstract}

Key words: adolescents; drug addiction; infractional acts; social networks.

O presente artigo discute os resultados de uma pesquisa de mestrado em Psicologia Clínica realizada entre 2001 e 2003. A pesquisa surgiu da demanda da Vara da Infância e Juventude de Brasília (VIJ-DF) ao Programa de Estudos e Atenção às Dependências Químicas - PRODEQUI (Laboratório do Departamento de Psicologia Clínica da Universidade de Brasília) de se implantar um programa de trabalho para adolescentes em conflito com a lei, referente ao fenômeno das drogas no contexto da Justiça.

Um dos grandes problemas enfrentados pela Vara da Infância e Juventude de Brasília (VIJ-DF) referia-se ao encaminhamento de adolescentes que chegavam ali por tráfico e uso de drogas. Existiam várias dúvidas em torno dessa questão, entre elas a de como identificar os riscos e controlar o consumo dessas substâncias.

A Justiça entendia que era necessário estabelecer parâmetros mínimos de tratamento e empreender a capacitação de profissionais na área, mas encontrava dificuldades, pois a rede de saúde pública não estava preparada para oferecer esse tipo de auxílio. No entanto, percebemos que era preciso, primeiramente, compreendermos melhor a atuação da Justiça junto ao adolescente em conflito com a lei, pois o nosso intuito era o

1 Endereço: SQN 213, Bloco A, Apartamento 402, Brasília, DF, Brasil 70872-010 E-mail: sandraeni@ hotmail.com de favorecer mudanças quanto à submissão do adolescente a uma medida que não fosse mais de controle, mas de proteção: o direito à saúde, ao atendimento e ao tratamento.

Precisávamos pensar sobre a contextualização do cenário, ou seja, sobre a realidade com a qual estávamos lidando. Mudamos, então, o direcionamento da problemática: o importante não era mais saber simplesmente se o adolescente era ou não usuário de drogas e para onde encaminhá-lo, mas o que fazer com isso.

Quem são os adolescentes que chegam todos os dias à Vara da Infância e Juventude de Brasília? O que eles pedem? O que eles pensam? Qual a sua realidade? Como abordá-los? Como encaminhá-los? Como evitar que entrem no circuito da delinqüência? E por que não direcionarmos essas questões ao "ator principal" desse contexto? Alguém saberia dar mais informações acerca do que pensam os adolescentes do que eles mesmos? Questionamentos como estes começaram a nortear nosso trabalho, despertando-nos interesse em ouvir os adolescentes em conflito com a lei, com a proposta de investigar, por meio de seus depoimentos, como eles percebiam a relação entre o ato infracional e o consumo de drogas na adolescência. Pretendíamos ampliar o "olhar" sobre o jovem envolvido com drogas, rompendo com a visão linear e reducionista, que estigmatiza o jovem ora como delinqüente, ora como doente e que propõe a idéia de causa e efeito entre a prática infracional e o consumo de drogas. 
Sustentados pelas abordagens sistêmica e psicossocial, fundamentação teórica do estudo, partimos do pressuposto de que, num contexto de pobreza e exclusão social, a drogadição não se limita a uma relação sujeito-produto, mas compreende o adolescente no seu contexto relacional sócio-familiar mais amplo, favorecendo sua inserção no circuito da delinquiência. Por isso, no caso do adolescente em conflito com a lei, não se trata apenas de identificar se seu envolvimento com a Justiça ocorreu por porte e uso de drogas, e assim encaminhá-lo ao tratamento. É necessário diferenciar os vários tipos e modalidades de uso das drogas (do usuário esporádico ao dependente), as características próprias de cada uma delas, o meio em que estão inseridas, assim como os níveis de dependência relacional que surgem em suas redes sociais. As demandas não são feitas somente no que diz respeito ao efeito das drogas, mas igualmente no que envolve os conflitos relacionais que geram a situação (Colle, 1996/2001).

\section{Fundamentação Teórica}

Antes de tratarmos os resultados da pesquisa propriamente ditos, é importante fazermos um breve comentário sobre alguns conceitos importantes, de modo que o leitor possa entender melhor, posteriormente, como compreendíamos tanto os adolescentes sujeitos da pesquisa como o que eles descreviam acerca do que lhes era perguntado.

\section{Adolescência}

O conceito de adolescência aqui é ampliado e contextualizado na relação. Ao direcionarmos nossa atenção ao estudo de questões que têm uma forte marca social, como é o caso da drogadição e da prática de atos infracionais na adolescência, não podemos negligenciar o contexto local, global e as diferentes situações que dão emergência a essas questões (Sudbrack \& Carreteiro, 2001).

As abordagens sistêmica e psicossocial não caracterizam a adolescência como um período único e inerente ao indivíduo, mas como um processo que ocorre em um dado momento, determinado na existência do sistema sócio-familiar, permitindo que haja uma desestigmatização do adolescente (Colle, 1996/2001).

A adolescência é a transição entre a dependência infantil e a autonomia adulta, caracterizada por transações afetivas relacionais, sociocognitivas, sexuais, identitárias e normativas, de lutos e desilusões, de prazer e gozo, as quais não ocorrem sem angústia ou conflitos (Selosse, 1997). Portanto, deve ser considerada como uma transformação social, mais do que biológica, de modo que, ao se tratar de dificuldades associadas aos adolescentes, passe a ser a única forma de pensamento capaz de conceituar os problemas e melhorar as possibilidades de um tratamento efetivo (Fishman, 1996).

\section{Redes sociais}

A compreensão do adolescente à luz do contexto de suas relações amplia nosso estudo em direção às redes sociais (família, amigos, escola, trabalho, comunidade), ou seja, às relações interpessoais que ele percebe como significativas ou que de alguma forma fazem parte de sua vida. É pela rede que o adolescente constrói seu universo relacional, reconhecendo-se como cidadão e construindo sua auto-imagem (Saidón, 1995; Sluzki, 1997).

Pakman (1995) descreve todo "ser" vazio em si mesmo, a não ser que faça parte de uma rede. $O$ indivíduo possui a dupla condição de, por um lado, ser idiossincrático, único, inacabável, não reconhecível, não representável (um "todo" em si mesmo) e ao mesmo tempo possuir uma natureza interacional: fazer parte de conexões com outras entidades em função das quais torna-se "o que é", revelando, assim, seu "vazio" intrínseco.

Durante toda a nossa vida, vivemos em grupos familiares, de amigos, profissionais, escolares, religiosos etc. Essa dimensão do ser é fundamental à estruturação da psique e da identidade, a qual é ao mesmo tempo singular e social. É impossível pensarmos sobre a nossa identidade sem pensarmos sobre os diferentes grupos aos quais pertencemos e a partir dos quais a construímos. "O indivíduo não apenas encontra-se em um grupo, em referência a outros grupos, mas esses grupos estão internalizados no indivíduo" (Rouchy, 2001, p. 130).

$\mathrm{O}$ conceito de rede social implica, portanto, um processo de construção individual e coletivo permanente. É um sistema aberto que possibilita o enriquecimento e a potencialização dos recursos que possui por meio do intercâmbio entre seus membros e com os membros de outros grupos sociais. "As aprendizagens diversas que uma pessoa realiza se potencializam quando são socialmente compartilhadas em busca da solução de um problema comum" (Dabas, 1995, p. 10). A aprendizagem se produz "na" e "através da" rede social: "O contexto social retroalimenta as percepções da realidade e vai criando signos, sinais, indicadores, através dos quais os jovens aprendem a construir o mundo e atuar nele" (Dabas, 1997, p. 64).

Ao observarmos o processo de construção das redes sociais dos adolescentes em contexto de pobreza e exclusão social, aproximando-nos mais da realidade dos participantes desta pesquisa, podemos perceber que as causas da exclusão não são apenas econômicas, mas principalmente identitárias, resultantes das diferentes posições ocupadas por ele (identidade social) e da relação subjetiva com essas posições (identidade psíquica), ou seja, de uma construção dinâmica na busca do jovem em se situar, em se posicionar e afirmar uma singularidade e unidade em face de uma realidade multiforme e heterogênea (Gaulejac, 1987).

Uma realidade que favorece a "descrença" em si mesmo e a ausência de esperança de uma vida melhor bloqueia toda a possibilidade de ação coletiva, o que provoca o "enfraquecimento das redes". Isso porque a função da identidade coletiva é justamente fornecer aos indivíduos de um grupo um modelo de identidade valorizante, de redes de solidariedade, um projeto de vida (Gaulejac \& Léonetti, 1994), e isso praticamente inexiste nesse contexto. A identidade coletiva é rompida por mecanismos repressores e preconceituosos que as próprias pessoas envolvidas constroem para si mesmas.

Os vínculos, portanto, fazem parte da nossa identidadeem-contexto. Por isso, a perda ou enfraquecimento desses vínculos produzem um "vazio de identidade, de história, de continuidade, de nutrição emocional, de feed-back social, de cuidados de saúde, de validação, de responsabilidade pelo outro..." (Sluzki, 1997, p. 26), o que contribui para o surgimento dos sintomas, como a drogadição e os atos infracionais. 


\section{Atos infracionais}

Existe uma forte evidência de que uma rede social pessoal efetiva, firme, sensível e confiável é geradora de saúde. Assim como existem evidências de que, quando uma pessoa está doente, deteriora-se a qualidade de interação com sua rede social, diminuindo o tamanho e a possibilidade de acesso a ela. Essa "dupla ação" está presente ao tratarmos questões relacionadas aos sintomas na adolescência. Quando as relações na adolescência são substanciais, elas protegem a saúde do adolescente, tanto quanto a saúde do adolescente é capaz de manter a efetividade de suas relações. Do mesmo modo, quando o adolescente passa a se comunicar por meio de um sintoma, ele ao mesmo tempo afeta e é afetado negativamente pelo seu sistema relacional (Sluzki, 1997).

Segundo Baumkarten (2001), a adolescência é permeada por momentos de mal-estar (depressão, sentimentos de perda, de abandono, de angústia, escolha de identidade), justamente por ser um período de constantes transformações. Os sintomas da adolescência, as condutas de risco (suicídio, transgressões, anorexia, bulimia, uso de drogas) surgem em função da capacidade de se conseguir enfrentar ou não esse mal-estar. Caso não encontre formas "saudáveis" de enfrentá-lo, o adolescente pode passar por um sofrimento intenso, marcado pela impossibilidade de se comunicar, a não ser pela somatização ou passagem ao ato.

Os sintomas aparecem quando há ruptura ou estagnação no desenvolvimento do ciclo de vida de uma família ou de algum outro grupo natural. "Os sintomas dos adolescentes são testemunhas do seu sofrimento, da sua vontade e simultaneamente da sua impotência para curar os sistemas relacionais" (Colle, 1996/2001, p. 196). Nesse sentido, a "transgressão" das normas é a forma encontrada pelo jovem de se comunicar com o outro; de denunciar um sofrimento coletivo; é mais um pedido de ajuda que uma afirmação em si.

Entre os comportamentos desviantes dos adolescentes, centramos nossa atenção naqueles que violam as leis sociais, que devem ser compreendidos também numa perspectiva relacional. Para Selosse (1997), os comportamentos sancionados pela violação das leis marcam a passagem das atividades derrogatórias às atividades repreensivas: os atos infracionais. Estamos falando agora de uma categoria particular referente ao "fora-da-lei", o qual nega toda troca e reciprocidade. A lei social passa a não ser mais desafiada, mas negada.

Foucault (1975/2000) define o "infrator" como aquele que infringiu as normas jurídicas estabelecidas, enquanto o "delinqüente" é a condição a que o sistema submete o indivíduo, estigmatizando-o e controlando-o, inclusive após ter cumprido a pena. Preferimos, portanto, utilizar aqui o termo "infração" ao termo "delinquiência" (Foucault, 1975/2000; Volpi, 1999).

Aqueles adolescentes que cessam seus comportamentos desviantes parecem achar uma via de auto-regulação nas suas relações, dando um novo sentido a elas, que se baseia na confiança, na cooperação, na igualdade e na reciprocidade. As normas deixam de ser percebidas no âmbito da coerção e passam a ser construídas no âmbito da interdependência. Quando isso não acontece, os jovens podem passar à prática de atos infracionais, demandando a mediação dos interditos. Em uma busca pela auto-afirmação, eles tentam provar que seus desejos podem modificar o real instituído.
Assim, quando não conseguem articular seus desejos com o interdito, utilizam-se de condutas violentas, infratoras, de modo a desconsiderar o interdito e substituí-lo pela "lei do mais forte", colocando em jogo o limite da vida: da sua e da do outro (Selosse, 1997).

Quando observamos o interior das famílias com adolescentes autores de atos infracionais, percebemos que os mecanismos seguros que protegem e garantem a sua sobrevivência parecem não funcionar (Garcia-Preto, 1995; Segond, 1992; Stanton \& Todd, 1985/1988).

Ferreira (citado por Sudbrack, 1992) levantou a hipótese da função parentalizada do juiz, ou seja, seu lugar simbólico como substituto do pai. As práticas infracionais viriam no sentido de buscar, fora da família, um terceiro, no caso o juiz ou o Sistema de Assistência Educativa. O juiz de Menores, por ser considerado uma figura de autoridade e proteção, substituiria o pai, na medida em que este falha como tal. Assim, as transgressões e a prática de atos infracionais corresponderiam a um "apelo à lei" que é falha na família, ou seja, ela teria fracassado em interditar.

Segundo Cauquil, Deckmyn e Sentis (citados por Blatier \& Chautant, 1999), os adolescentes em conflito com a lei são rejeitados pela família, pela escola, pelo mundo do trabalho e pelas instituições de um modo geral. Por isso eles criam uma nova realidade, com seu próprio código, que corresponde à vida delinqüiente. Suas carências afetivas ou seus desvios de personalidade encontram-se relacionados com a vida que tiveram: seu lugar na família, com uma mãe ambivalente (ora o supervaloriza, ora o desvaloriza) e um pai ausente ou muito autoritário, com atos repreensivos, às vezes imperceptíveis ou muito fortes, mas sempre inadequados.

Pain (1999) refere-se a esses adolescentes como jovens (des)identificados, diferente de "mal identificados" ou "não identificados", pois marcam uma ruptura de identificação com o sistema, ou seja, expressam a idéia de cessar, de colocar um fim. É como se o adolescente se retirasse das construções identificativas, mantendo-se à distância delas, mediante uma recusa inconsciente do outro ou de uma defesa em encontrar o outro, o mito do "encontro falho", que é o componente-chave da violência. Mas não se pode esquecer que são adolescentes e que eles não encontraram sua imagem no "olhar social". Segundo Monteiro (1999), a seqüência de perdas e exclusões por que passam esses adolescentes aumenta o medo em relação ao bem-estar social e à morte. Colocam-se ora na posição de vítimas (com relação à discriminação que sofrem), ora na de vitimizadores (intimidando todo o bairro). Temem e idolatram ao mesmo tempo os marginais, afrontando a ordem vigente e se rebelando contra a falta de direitos. Tornam-se violentos para ganharem uma identidade entre os seus, para serem reconhecidos, combatendo o temor da própria morte (Velho, 1996; Zaluar \& Leal, 2001).

\section{Drogadição}

Neste momento, direcionamos nossa atenção à principal questão deste trabalho: o adolescente que está envolvido com drogas e que comete algum ato infracional pelo seu envolvimento com elas.

O problema do uso de drogas se dá pelo encontro de um produto, de uma personalidade e de um momento sócio-cultu- 
ral, ou seja, a droga não é mais simplesmente um produto, mas um fenômeno que não pode ser estudado sem que esteja incluído em todo seu "universo relacional" (Olivenstein, 1985)

Dentro desse universo relacional, no que se refere às relações com a família, Colle (1996/2001) afirma que o comportamento desviante, associal e alienante do adolescente é, muitas das vezes, um reforço do elo familiar. A autoridade parental em famílias com um adolescente com problemas pelo uso de drogas é comprometida, apresentando repertório pobre de regras e limites (ordens, advertências e ameaças vazias), assim como indefinição hierárquica ou confusão de funções e papéis entre os membros do sistema familiar.

Direcionando o olhar ao sistema sociofamiliar mais amplo, Velho (citado por Espinheira, 2002) relaciona o "mundo das drogas" a "redes sociais que organizam sua produção, distribuição e consumo, bem como a conjuntos de crenças, valores, estilos de vida e visões de mundo que expressariam modos particulares de construção social da realidade" (p. 14). Nessa mesma linha de raciocínio, evidenciamos que o mundo das drogas produz a cultura das drogas: "os grupos em sua singularidade desenvolvem conhecimentos a respeito das drogas que utilizam, compartilhando essas experiências e estabelecendo normas e formas de uso" (Espinheira, 2002, p. 14).

O termo "drogadição" é utilizado aqui, portanto, como uma expressão que permite alargar o estudo a um conjunto de relações e comportamentos, e não simplesmente ao comportamento individual ou ao estado provocado pela droga. A atenção pura e simplesmente à dependência do produto oculta, muitas vezes, as "dependências relacionais". E como temos percebido, nos sistemas da drogadição existe pelo menos uma outra pessoa envolvida, além do usuário (Colle, 1996/2001).

Quem é o dependente? De quem ele é dependente? De quê? Como? Por quem? A que preço? A partir da compreensão do fenômeno das drogas centrada “na relação", Colle (1996/2001), numa análise das co-dependências das drogas, propõe seis níveis lógicos de dependência relacional que mostram a complexidade da dependência para os usuários. São elas: a dependência dos efeitos, que mostra a relação do usuário com os efeitos e as formas de uso de uma ou várias substâncias consumidas simultânea ou sucessivamente. As dependências relacionais afetivas, que se referem às relações do casal e da família, partindo-se do pressuposto de que, dentro do círculo de relações do dependente de drogas, há pelo menos uma pessoa co-dependente, essas pessoas podem ser ou ter sido igualmente dependentes de drogas. A dependência dos fornecedores, ou seja, a dependência das pessoas implicadas no sistema de distribuição. Avalia-se nessa dimensão a relação do usuário com as pessoas que vendem ou passam a droga para eles. A dependência dos provedores, isto é, a dependência das relações com as pessoas que lhe asseguram a possibilidade de adquirir a droga, do ponto de vista financeiro; aquelas pessoas que lhe dão o dinheiro para comprar a droga, podendo ser tanto o pai ou a mãe como um traficante que lhe dá a droga em troca de serviços prestados ao tráfico. A dependência dos pares: diz respeito à rede de parceiros envolvidos no intercâmbio de informações e de endereços, no compartilhamento do uso, nas eventuais ajudas, na cultura da droga. Por fim, a dependência das crenças, que se refere à crença na eficácia da dependência, ou seja, a crença comum de que as drogas vão restabelecer o indivíduo em suas dificuldades pessoais e relacionais; a crença de que a droga é necessária para se ter um novo estado de ânimo; a crença na "magia" do produto.

Apesar da divisão em "níveis de dependência" facilitar nossa compreensão acerca do fenômeno da drogadição e sua relação com o ato infracional, esses níveis são interdependentes, ou seja, uma mesma pessoa pode exercer várias funções co-dependentes, o que permite alargarmos ainda mais nosso olhar para a complexidade das relações construídas no contexto da pesquisa.

\section{Método}

A metodologia utilizada para este estudo foi de caráter indutivo e exploratório, de cunho qualitativo. A intenção do estudo, como sustenta a pesquisa qualitativa, foi a de construir argumentos, não esgotá-los. Os resultados obtidos aqui foram, portanto, momentos parciais, que podem abrir novos caminhos, suscitar outras dúvidas, despertar novas indagações e trazer contribuições para os próximos estudos acerca desse fenômeno tão complexo como o da drogadição e da prática de atos infracionais na adolescência (Demo, 1997; González-Rey, 2002).

As informações foram coletadas por meio de 29 entrevistas semi-estruturadas aplicadas em adolescentes autores de atos infracionais, no contexto da Vara da Infância e Juventude de Brasília (VIJ-DF). A amostra foi constituída, tendo como critério apenas a disponibilidade dos adolescentes que aguardavam a oitiva informal (audiência com o Promotor), junto à Promotoria da VIJ-DF, no período de permanência da pesquisadora na instituição. Resultou, portanto, num grupo heterogêneo quanto à faixa etária, aos tipos de infração cometidos e às medidas socioeducativas recebidas. Quanto à origem socioeconômica, houve a predominância de adolescentes de contextos desfavorecidos, de pobreza e exclusão social. Embora não tenha sido sistematizado o perfil socioeconômico dos adolescentes sujeitos da pesquisa, esta dimensão ficou evidenciada pela observação dos entrevistadores no decorrer dos relatos. Todos os adolescentes assinaram um Termo de Consentimento Livre e Esclarecido, concordando em participar da pesquisa sob condições de anonimato e voluntariado para iniciar e interromper a entrevista.

As informações obtidas foram submetidas a análise de conteúdo do tipo construtivo-interpretativo proposto por González-Rey (2002), que implica o enfoque teórico adotado pelo pesquisador, os processos intelectuais decorrentes de suas interpretações e a complexidade da relação entre essas interpretações e o estudado, os quais se encontram na construção de indicadores, categorias e zonas de sentido. Essas operações interpretativas não se orientam para a produção de resultados finais universais e invariáveis, mas encaram a investigação como um processo, permitindo o avanço na construção teórica do que é estudado, o que seria, em outras palavras, a legitimação do conhecimento.

\section{Discussão dos Resultados}

Dividimos a análise dos resultados em categorias para atender às dimensões do conceito de dependência de Colle (1996/2001) (dependência dos efeitos, das crenças, relacionais afetivas, dos pares, provedores e fornecedores) e facilitar a visu- 
alização e interpretação dos resultados. Algumas falas dos adolescentes entrevistados aparecem para fomentar a discussão.

\section{Ato infracional e dependência dos efeitos}

Segundo relato dos adolescentes, a droga possui uma fase de encantamento: atrai o jovem pelo prazer, facilita suas relações e espaços em novas redes e incita o desejo pela tomada de risco. Em um segundo momento, revela seus efeitos desagradáveis, de sofrimento e descontrole pela passagem do uso ocasional ao uso mais frequiente, abusivo, das drogas. Por fim, num terceiro momento, há uma relação com a droga na qual o jovem já não dá conta de fazer suas ações diárias sem estar sob o efeito dela. Aqui sim, há um indício de dependência.

Talvez possamos entender a dimensão da "dependência dos efeitos" das drogas como um processo, uma passagem do uso recreativo ao abuso e à descoberta da dependência. Essa passagem pode sim ocorrer, mas pode ser também que não ocorra. Isso porque tanto o efeito da droga como a duração deste no organismo costumam ser variáveis entre os adolescentes. Dependem de uma diversidade de fatores, tais como: o tipo, a quantidade e a qualidade da droga; as formas de uso; as características pessoais do adolescente; suas expectativas em relação aos efeitos; e o contexto do uso propriamente dito.

Além disso, nos relatos dos adolescentes percebemos como eles relacionam a dependência dos efeitos ao ato infracional. Uma das articulações descritas é o fato de que cometem o delito para usar a droga: "Se faz de tudo para ter drogas: matar, roubar". Os relatos mostram a percepção do ato infracional em decorrência da dependência da droga, ou seja, o ato infracional como funcional à droga. Nesse caso, as drogas consideradas "duras" (merla, crack, por exemplo) ${ }^{2}$ (Xiberras, 1989) são as mais citadas pelos jovens, pois provocam crises de abstinência mais intensas, e por isso os usuários tornam-se mais agressivos e capazes de qualquer coisa: "Roubo e mato para ficar sempre no mesmo efeito". Os delitos mais cometidos nesse caso são o roubo e o furto, buscando o dinheiro para comprar a droga. Segundo os adolescentes, "não existe roubar por causa de maconha; agora, por merla, cocaína, essas outras, ele sente a necessidade, sente falta, e não tem onde conseguir e rouba."

No entanto, o fato de cometerem o ato infracional para usarem drogas é apenas um sinal de dependência da droga ou poderia ser também uma estratégia de sobrevivência? Em contextos desfavorecidos, não podemos deixar de pensar também nas estratégias que esses jovens desenvolvem na tentativa de eliminar o frio, a fome, como também a dor, o sofrimento, o abandono e a solidão.

Outra informação importante trazida pelos adolescentes: quando cometem o delito por estarem sob o efeito da droga. "Hoje, se você usar um rohypnol, você vai matar uma pessoa e não lembra... No dia que a gente foi presa, eu já tinha

2 Na década de 1990, enquanto em tantas outras localidades, principalmente em São Paulo, surgia o crack (cocaína em forma de base, fumada em "cachimbos") como substituto dos inalantes, em Brasília surgia uma nova substância, também feita do substrato da cocaína e fumada, de fácil fabricação, ainda sem refino e muito contaminada com as substâncias utilizadas na extração, mais barata que a cocaína e de efeitos muito mais intensos: a merla. bebido, fumado maconha e cheirado coca...”. Aqui há uma outra dimensão levantada pelos adolescentes da relação entre a dependência dos efeitos das drogas e os atos infracionais. $\mathrm{O}$ ato infracional é percebido como decorrente dos efeitos da droga. É interessante observar que, nesse caso, as práticas infracionais são geralmente acompanhadas de condutas de violência: agressões físicas e tentativas de homicídio. Poderíamos então nos perguntar: Será que a droga está "gerando" a violência (como é tão falado em nossa sociedade) ou "despertando-a" nesses jovens?

Por um lado, sabemos que comportamentos violentos podem ser gerados pelas drogas. A merla e o crack, por exemplo, são drogas mais baratas, mais acessíveis em contextos desfavorecidos, além de terem efeitos mais intensos. Segundo Baumkarten (2001), quando fumadas, essas drogas podem levar à compulsão, provocar dependência rápida, euforia, paranóia, delírios persecutórios e um desejo intenso por mais droga. Não conseguindo permanecer sem seus efeitos, os usuários procuram não dividi-las com mais ninguém e são até mesmo capazes de atos violentos contra as pessoas, pois sentem fortes sensações de angústia, ansiedade e desespero: "a pessoa fica nervosa, com uma fobia e tal e começa a agredir as pessoas dentro de casa".

Por outro lado, não podemos deixar de pensar na possibilidade de esses adolescentes estarem liberando, por meio da droga, uma agressividade contida, reprimida. Esses jovens encontram-se vulneráveis pelo contexto de exclusão em que vivem. Passam por situações altamente frustrantes e tensas e não encontram um modo de expressar os sentimentos de raiva e revolta que são despertados. A droga aparece como "válvula de escape" para suas tensões, mas ao invés de controlar o sentimento, libera-o em maior intensidade, pois ela rompe com todos os mecanismos de censura.

\section{Ato infracional e dependência das crenças}

São adicionadas a todo esse processo, as representações sociais criadas em torno do produto e de seus efeitos, ou seja, a crença na magia da droga. Em um contexto de pobreza e exclusão, em que os problemas enfrentados são os mais diversos, agravados pela introjeção de uma auto-imagem negativa, pela descrença em si mesmo e pela ausência de esperança de melhores condições de vida, esses jovens, além de desejarem esquecer os problemas e encontrar momentos de prazer, passam a acreditar que com a droga podem tudo, que a droga é capaz de lhes oferecer "poder" e "coragem" para desafiarem, conquistarem ou violarem: "as pessoas buscam 'ibope' e um desabafo."

A relação entre a drogadição e o ato infracional adquire uma nova representação para eles: usam a droga para cometerem o delito: "quando usa droga a pessoa cria coragem pra fazer tudo, inclusive o crime". A droga aparece agora como funcional ao delito, diferentemente do que foi comentado anteriormente, quando descrevíamos sobre a dependência dos efeitos. Ali, os adolescentes relatavam cometer o delito para usar a droga, ou seja, ela aparecia como anterior ao delito; os adolescentes, por dependência e compulsão pela droga, praticavam atos infracionais para consegui-la.

Já nessa nova representação, em que usam a droga para cometer o ato infracional, estão se referindo mais à questão 
da crença de que a droga pode restabelecê-los em suas dificuldades pessoais e relacionais; não é mais uma questão de dependência ou compulsão, mas uma questão de acreditarem que a droga é necessária para lhes oferecer um novo estado de ânimo, tornando-os capazes de cometer o delito: "A pessoa já quer praticar a violência e usa a droga pra ter coragem."

Percebemos pelos relatos que, nessas circunstâncias, o ato infracional tem se tornado cada vez mais grave, mais violento e não mais contra os desiguais, mas entre o próprio grupo de pares, mostrando como esses jovens já incorporaram uma visão violenta da vida, permeada pela banalização da morte.

Além disso, a droga pode também representar uma justificativa para o ato infracional: "não fui eu, foi a droga". Os adolescentes relatam terem feito uso de álcool e/ou drogas no momento da infração apenas para justificarem seus atos, pois, na verdade, a infração seria cometida de qualquer forma, estando ou não sob o efeito das drogas. Os adolescentes denunciam então o mito de que a droga é a "grande" responsável pela violência, passando a ser apenas uma boa forma do adolescente se defender perante a Justiça, perante a família, perante o olhar do outro, eximindo-se da responsabilidade por seus atos.

Além das dependências do produto, relacionadas aos efeitos e às crenças, podemos continuar nossa reflexão, abordando uma outra dimensão traçada neste estudo, que se refere às dependências de contexto, ou seja, às dependências relacionais afetivas, dos pares, do provedor e do fornecedor. Os adolescentes apontam uma estreita relação entre o contexto e as práticas infracionais.

\section{Ato infracional e dependências relacionais afetivas}

Quanto às dependências relacionais afetivas, existe um potencial afetivo importante na família. Os adolescentes descrevem um vínculo forte com a mãe, revelando e valorizando o papel protetivo, acolhedor e de defesa da mãe quando do seu envolvimento com a Justiça. Este é, muitas das vezes, o vínculo mais forte apresentado pelo adolescente autor de ato infracional em relação à sua rede social. Ao passo que a mãe o protege, ele também age no mesmo sentido, procurando mostrar sua admiração, confiança, lealdade e proteção em relação a ela.

Por isso, entendemos que a atuação da mãe no contexto infracional pode trazer grandes contribuições para as possíveis mudanças de comportamento e desenvolvimento emocional adequado do filho. Mas o que tem impedido tais mudanças talvez seja o fato de essas mães mostrarem-se permissivas ao comportamento transgressor dos filhos, perdendo sua autoridade diante deles. Chegam a negar a situação ou a guardar segredo do problema, com a intenção de minimizar os riscos e resolver o problema sozinhas. Os filhos não se responsabilizam por seus atos, pois contam com o apoio delas: "Família é só minha mãe e minha irmã. Minha mãe não gosta, claro, tem medo que eu morra, suma, seja preso... Mas para minha mãe, que é quem importa, não muda nada. Ela sabe como eu sou e gosta de mim do mesmo jeito. Ela sabe o filho que tem."

Com relação ao pai, encontramos nos relatos: "O bicho não me vê, não me procura, não quer saber de mim, me esqueceu, não sabe nem que tem filho. Estragou minha vida, estragou a vida da minha mãe. Quando a gente morava junto, chegava bêbado, batia na gente, batia na minha mãe. Nós tinha que sair de casa, esperar o bicho dormir pra voltar. Era briga todo, todo, todo dia". Emerge, então, a ausência do papel afetivo, protetivo e de autoridade do pai; emerge a falta do pai; um sentimento de frustração pela falta de atenção, rejeição ou abandono desse pai; uma falta de qualidade no vínculo pai-filho. O pai aparece sempre distante, sem intimidade ou disponibilidade para estar com seu filho. A função paterna fica comprometida, fazendo com que o jovem permaneça no vazio e procure "fora" a autoridade que não encontra "dentro" de casa. O ato infracional pode surgir como a busca do pai ausente, da autoridade, de uma lei que seja capaz de colocar limites, que "proíba" o adolescente de agir, mas que favoreça, em contrapartida, algum tipo de aproximação pai-filho (Bulaccio, 1992; Omer, 2002).

É interessante ressaltarmos que a desestruturação de uma família, seja pelo divórcio, pela morte de algum membro, seja por razões socioeconômicas, pela ação direta da pobreza ou pela baixa escolaridade, não são fenômenos que, por si só, levam à drogadição. Mas a ausência de afetividade dentro de um sistema familiar, esta sim é a grande responsável por fenômenos como a drogadição e as práticas infracionais, pois a única coisa impossível de ser substituída na vida das pessoas é o amor (Kalina \& cols., 1999).

Ainda com relação às relações familiares, um outro aspecto a ser considerado refere-se à denúncia do alcoolismo do pai e/ou outros usuários de drogas e antecedentes criminais na família como mediadores do vínculo. Essa questão nos leva a pensar no significado simbólico para o adolescente do comprometimento de algum membro da família com o álcool, as drogas ou os atos infracionais. Aparecem contradições nos relatos dos adolescentes. Se, por um lado, vêem as condutas "alcoolistas", aditivas e delituosas no sistema familiar como "modelo" (não há críticas em relação ao pai ou outros membros da família), sendo o próprio sistema que os introduz na criminalidade e na adição (aprendem com o pai a beber, a traficar), por outro lado, os adolescentes denunciam os membros do sistema. A falta de coerência no contexto familiar torna a relação ambivalente: abandono e regresso, aproximação e distanciamento, provocando nos adolescentes sentimentos também bastante contraditórios. Se em determinados momentos odeiam, rejeitam, estigmatizam seus familiares quando estes se tornam inconvenientes por perderem o controle da situação, em outros, amam-nos, são cúmplices e os têm como exemplo. Podemos pensar que toda a situação é conflituosa e pode estar deixando o adolescente mais vulnerável a ficar fora de casa.

\section{Ato infracional e dependência dos pares}

Na adolescência, percebemos a importância da rede dos pares na busca de identidade e autonomia do jovem, que pode ser, ao mesmo tempo, uma rede de risco e proteção. Quando pesquisamos sobre a relação do adolescente em conflito com a lei com os pares, percebemos momentos e sentimentos diferentes vividos por ele em relação ao grupo, até o envolvimento com a justiça.

Quando da busca de socialização e da constituição de um grupo de pertença, o adolescente vive um primeiro estágio: o da "ilusão". Acredita que o grupo lhe dará segurança, 
protegendo-o do abandono, da repressão da família, das precariedades econômicas. Por isso, quando inicia o consumo de drogas, este pode ocorrer, em primeira instância, pela pressão dos pares: o consumo de drogas como possibilidade de inserção no grupo. "Ninguém usa droga à toa, é a influência de alguém, de algum amigo". A necessidade de se sentir pertencente ao grupo é anterior à necessidade da droga e esta, conseqüentemente, é vista como facilitadora do vínculo, como fator de inserção no grupo de pares, como meio para a formação de uma imagem e identidade grupal. Ao mesmo tempo, pode funcionar como uma válvula de escape aos conflitos identitários, sociais, familiares e sexuais: "É o dia-a-dia, assim, a discussão com a família... ou os seus amigos que te chama e eles já tá... chega assim, revoltado, aí vai fumar, aí sei lâ". Assim, os grupos de pares vão se construindo, marcados pela filosofia do consumo, numa relação paradoxal de inclusão-exclusão: se não usa drogas, não pertence ao grupo.

Nos caminhos equivocados percorridos pelo adolescente ao se inserir no mundo dos pares, ele se "decepciona" com o grupo. $\mathrm{O}$ adolescente passa a culpabilizá-lo pelo seu fracasso e começa a construir uma imagem negativa dos pares: não existe amizade no mundo das drogas. "Não existe amizade, pois amigo não te droga... As amizades certas pensam em crescer, os que mexem com drogas só pensam em coisas ruins: roubar, matar". O grupo de consumo não é fiel à amizade, mas à droga. "Os viciados não são amigos, porque os amigos de verdade não querem o mal dos outros. Quem usa droga junto é parceiro, porque tá junto só naquela hora".

No entanto, esse adolescente que vive em contexto de desagregação e exclusão social, marcado pela fragilidade dos laços sociais, pela incapacidade de organização e por um forte sentimento de insegurança, introjeta sua própria condição histórico-social como característica negativa pessoal, sentindo-se inferior, incapaz, desvalorizado. Ao mesmo tempo, é esse mesmo sentimento comum de insegurança que estabelece a rede de relações entre eles, mesmo que esta não seja "ideal". "Muita gente já fez como eu: fez um homicídio, tráfico. Já rodamos por causa das mesmas coisas. Quase cinqüenta por cento das pessoas da rua têm envolvimento com a Justiça". Por isso, passa por um terceiro momento, que é quando ele se "conforma" com a situação e percebe a droga e o delito como partes do cotidiano. Não consegue enxergar novos horizontes, não consegue ver outras possibilidades de resgatar vínculos diferentes: esta é a sua realidade, o seu contexto. $\mathrm{O}$ jovem encontra no mundo das drogas e da criminalidade a sua rede de pertença e aceita fazer parte dela. O grupo é ruim, mas é a sua única referência de grupo. Resolve, então, "adequar-se" ao grupo tal qual ele é, ou seja, adequar-se à cultura da marginalidade, às leis da rua: "Às vezes, nos ajudamos, depende. Te falo como é: se te batem, te ajudam a matar... Se tá todo mundo junto, resolvem fazer alguma coisa dessas, tá todo mundo envolvido, porque você não vai largar um amigo na mão".

\section{Ato infracional e dependência do provedor}

Quando perguntado aos adolescentes sobre quem provê a droga para eles, a grande maioria não vê outra possibilidade de aquisição que não seja pela prática infracional ou pelas trocas entre os pares. Quando o provedor é o ato infracional, o adolescente rouba e aqui o provedor é a vítima; ou trafica, isto é, o provedor é o cliente. É uma dupla contravenção, pois inclui roubo/tráfico e consumo de drogas (Bucher, 1992). "Quando você não tem a fonte, dinheiro da mãe ou do serviço (tráfico), pega revólver emprestado e rouba mesmo". Nesse caso, a inserção no mundo da criminalidade se dá pela dependência do provedor e o ato infracional é novamente funcional à droga.

Já no contexto onde os pares são provedores de drogas, isso parece acontecer somente se existir um relacionamento de muita confiança entre eles. "Não precisa de dinheiro não. Qualquer lugar você encontra, mas se é conhecido há muito tempo e a relação é boa".

Os contextos de dependência do fornecedor e do provedor são os mais presentes na vida do consumidor, mas também são os mais temidos. O sistema de distribuição da droga é considerado ameaçador, violento e com regras rígidas a serem seguidas. Por isso, há certa dificuldade de encontrar provedores entre os pares, a menos que a relação seja de confiança mútua, para que nem provedores, nem usuários corram riscos com o tráfico.

Segundo a Secretaria de Estado de Ação Social do Distrito Federal (SEAS/DF), os adolescentes que prestam serviços ao tráfico em troca de drogas recebem também armas e proteção dos comandantes do tráfico em suas comunidades, o que tem favorecido o agravamento dos tipos de atos infracionais cometidos por eles.

\section{Ato infracional e dependência do fornecedor}

Avaliando, por fim, a dimensão da relação dos adolescentes com as pessoas que vendem ou passam a droga para eles, percebemos que existe uma grande violência do contexto na relação com o fornecedor, ou seja, a violência do contexto do tráfico sobre o jovem é maior que a violência do próprio jovem.

Diante das inúmeras dificuldades encontradas pelos jovens, o tráfico aparece como a melhor opção de trabalho. Os jovens temem, mas ao mesmo tempo idolatram o mundo do crime, pois inserir-se nesse mundo é uma forma de se rebelarem contra o sistema vigente.

Para a inserção dos adolescentes no tráfico, existem questões que vão além de um "simples" fator econômico, mas que contemplam a especificidade dessa nova criminalidade, como por exemplo: quem estabeleceu e como se estabeleceram os valores que levam os jovens à busca incessante pelo prazer e pelo poder? A princípio, o tráfico confere-lhes sim, prazer e poder, e constitui-se numa rede de pertença, uma rede que os jovens não têm: a "minha" escola, a "minha" igreja, a "minha" família etc. Tornam-se "marginais", "delinqüentes" para adquirirem talvez uma identidade, um reconhecimento entre os seus. Apesar disso, ao se envolverem com o mundo do tráfico, os jovens perdem a sua liberdade. Ao construírem uma "carreira" dentro das organizações criminosas, dificilmente conseguem reverter essa trajetória (Minayo, 1997; Monteiro, 1999).

As relações entre os fornecedores e entre estes e seus clientes são permeadas pela desigualdade, ameaças, violência e submissão. Podemos pensar que essa relação faz parte das regras e hierarquias bastante rígidas e violentas estabelecidas nesse submundo da criminalidade. O mercado das drogas gera violência entre consumidores e fornecedores por uma 
variedade de circunstâncias que estão fadados a viver: disputa por territórios, disputa pela qualidade e quantidade de drogas, roubo de dinheiro ou do produto, o que determina as práticas bárbaras e violentas, de opressão e divisão, que se tornam estratégias para disciplinar o mercado (Minayo, 1997).

Tanto fornecedores quanto consumidores encontram-se desprotegidos, pois passam a não mais se importar uns com os outros, mantendo-se numa relação individualista e egoísta do "cada um por si". Não existe solidariedade, companheirismo, amizade, afeto. O vínculo é visto como uma ameaça, podendo trazer problemas aos "negócios". Por isso, a relação que se estabelece entre fornecedor-consumidor é baseada apenas na comercialização da droga, ou seja, é "estritamente profissional" (de compra e venda).

\section{Considerações Finais}

Tudo isso parece por demais contraditório, mas são as artimanhas da relação complexa. A voz do adolescente em conflito com a lei denuncia as contradições, mas ao mesmo tempo a complementaridade que existe entre os níveis de dependência e entre estes e a prática de atos infracionais. São dimensões distintas, o que não supõe que sejam excludentes entre si. Ao contrário, conectam-se de acordo com a dinâmica das relações dos adolescentes no seu contexto sócio-familiar mais amplo, por isso as contradições que encontramos na $\mathrm{VOZ}$ dos adolescentes entrevistados. Isso significa que devemos ampliar nosso olhar, pois são "diferentes" adolescentes, reagindo de "diferentes" formas a uma "mesma" situação, o que nos afasta da idéia de que precisamos de respostas únicas para situações complexas. Em outras palavras, o que nos faz compreender a relação entre o ato infracional e o consumo de drogas na perspectiva da complexidade (Morin, 1996, 2001).

A busca de caminhos para o fenômeno da transgressão carece de uma visão que se distancie das noções estigmatizadoras do diverso. Como propõe Monteiro (1999), estudar esses fenômenos requer, mais do que trabalhar umas poucas opiniões e fatos isolados, uma ação complexa, com uma multiplicidade de olhares, que permitam apreender "a bela e a fera" da questão, tanto no que se aproximam, quanto no que se distanciam, isto é, em suas semelhanças e diferenças.

O nosso trabalho procurou compreender melhor o adolescente e sua visão acerca dos fenômenos da drogadição e da prática de atos infracionais, responsáveis pelo sofrimento da família e pela demanda da Justiça. Acreditamos que, à medida que compreendemos melhor esse sintoma e sua complexidade, é possível trazer contribuições, a fim de amenizar o sofrimento dessas famílias e avançar na construção de novas metodologias de intervenção, no âmbito da Justiça.

Do ponto de vista social, o adolescente é ainda estigmatizado ora como vítima (produto do meio em que vive), ora como agressor (responsável único pela prática do ato infracional), ora como doente (portanto precisa de tratamento) ou como delinqüente (deve ser punido). Essas são visões excludentes e simplistas, que se limitam ao controle do comportamento do adolescente. Além disso, o estigma não permite a redução significativa dos seus problemas de conduta e não possibilita nenhuma mudança positiva, nenhuma melhora nas suas relações afetivas. Ao contrário, o adolescente perde sua autonomia e sua voz.
Abordamos aqui a importância de se pensar numa perspectiva mais complexa de intervenção. Entendemos que a abordagem da redução de danos e o trabalho em rede são possibilidades que hoje encontramos, no sentido de compreendermos e avançarmos na construção de novas formas de intervenção junto ao adolescente usuário de drogas e autor de atos infracionais. "Ao invés de colocarmos barreiras ou apenas delimitarmos fronteiras, estamos nos propondo a edificar pontes, formar elos, articular saberes, em uma construção conjunta de modelos que ampliem cada vez mais nossa visão de mundo" (Sudbrack, 1996, p. 108).

\section{Referências}

Baumkarten, S. (2001). O significado da drogadição no contexto da adolescência, da família e da instituição - um estudo sobre usuários e abusadores de merla do Distrito Federal. Tese de Doutorado, Universidade de Brasília, Brasília.

Blatier, C. \& Chautant, C. (1999). Mineurs délinquants aux limites de la prise en charge. Bulletin de Psychologie, 52(3), 321-328.

Bucher, R. (1992). Drogas e drogadição no Brasil. Porto Alegre: Artes Médicas.

Bulaccio, B. (1992). Família e a clínica da drogadição. Psicologia: Teoria e Pesquisa, 8(Suplemento), 459-468.

Colle, F. X. (2001). Toxicomanias, sistemas e famílias: onde as drogas encontram as emoções. (M. J. Pereira, Trad.) Lisboa: Climepsi editores. (Trabalho original publicado em 1996)

Dabas, E. (1995). A Intervenção em rede. Nova Perspectiva Sistêmica, 4(6), 5-17.

Dabas, E. (1997). Red social, sistema familiar y aprendizaje. Sistemas Familiares, 3(13), 63-69.

Demo, P. (1997). Conhecimento moderno: sobre a ética e intervenção do conhecimento. Petrópolis: Vozes.

Espinheira, C. G. A. (2002). Os tempos e os espaços das drogas. Entre riscos e danos: uma nova estratégia de atenção ao uso de drogas (pp. 11-18). União Européia e Governo do Brasil: ACODESS.

Fishman, H. C. (1996). Tratando adolescentes com problemas: uma abordagem da terapia familiar. Porto Alegre: Artes Médicas.

Foucault, M. (2000). Vigiar e punir: nascimento da prisão. (R. Ramalhere, Trad.) Petrópolis: Vozes. (Trabalho original publicado em 1975)

Garcia-Preto, N. (1995). Transformação do sistema familiar na adolescência. Em Carter,B. \& Mcgoldrick, M. As mudanças no ciclo de vida familiar: Uma estrutura para a terapia familiar (pp. 223-247). Porto Alegre: Artes Médicas.

Gaulejac, V. (1987). La névrose de classe: trajectoire sociale et conflits d'identitè._Paris: Hommes \& Groupes Editeurs.

Gaulejac, V. de \& Léonetti, I. T. (1994). La lutte des places: insertion et désinsertion. Paris: Desclée de Brouwer.

González-Rey, F. (2002). Pesquisa qualitativa em psicologia: caminhos e desafios. São Paulo: Pioneira Thomson Learning.

Kalina, E., Kovadloff, S., Roig, P. M., Serran, J. C. \& Cesarman, F. (1999). Drogadição hoje: indivíduo, família e sociedade. Porto Alegre: Artes Médicas.

Minayo, M. C. S. (1997). A complexidade das relações entre drogas, álcool e violência. Em M. Babtista \& C. Inem (Orgs.), Toxicomanias: uma abordagem multidisciplinar (pp. 33-42). Rio de Janeiro: Sette Letras.

Monteiro, S. I. (1999). Tentando compreender Prometeu e Dionísio na mira da violência. Cadernos Cedes, 19 (47), 67-80. 
Morin, E. (1996). A noção de sujeito. Em Schnitman, D.F (org.). Novos paradigmas, cultura e subjetividade (pp. 45-58). Porto Alegre: Artes Médicas.

Morin, E. (2001). Ciência com consciência. Rio de janeiro: Bertrand Brasil.

Olivenstein, C. (1985). A clínica do toxicômano: a falta da falta. Porto Alegre: Artes Médicas.

Omer, H. (2002). Autoridade sem violência: O resgate da voz dos pais. Belo Horizonte: Artesã.

Pain, J. (1999). L'adolescent sans pitié. Le bal du vampire et de la méduse. Bulletin de Psychologie, 52(3), 329-336.

Pakman, M. (1995). Redes: una metáfora para práctica de intervención social. Em E. Dabas \& D. Najmanovich (Orgs.), Redes el lenguaje de los vínvulos: Hacia la reconstrucción y el fortalecimiento de la sociedad civil (pp. 294-302). Buenos Aires: Paidós.

Rouchy, J. C. (2001). Identificação e grupos de pertencimento. Em J. N. G. Araújo \& T. C. O. Carreteiro (Orgs.), Cenários sociais e abordagem clínica (pp. 123-140). São Paulo: Escuta; Belo Horizonte: Fumec.

Saidón, O. (1995). Las redes: pensar de outro modo. Em E. Dabas \& D. Najmanovich (Orgs.), Redes el lenguaje de los vínvulos: Hacia la reconstrucción y el fortalecimiento de la sociedad civil (pp. 203-207). Buenos Aires: Paidós.

Segond, P. (1992). Família e transgressão. Psicologia: Teoria e Pesquisa, 8(Suplemento), 433-446.

Selosse, J. (1997). La réparation dans lê champ éducatif. Em J. Pain \& L.M. Villerbu (Orgs.), Adolescence, violences et déviances (1952-1995) (pp.76-85), Vigneux: Éditions Matrice.

Sluzki, C. E. (1997). A rede social na prática sistêmica. São Paulo: Casa do Psicólogo.

Stanton, M. D. \& Todd T. C. (1988). El modelo terapéutico. Em M. D. Stanton \& T. C.Todd (Orgs.), Terapia familiar del abuso y adiccion a las drogas (C. Gardini, trad., pp 101-159). Buenos Aires: Gedisa. (Trabalho original publicado em 1985)

Sudbrack, M. F. O. (1992). Da falta do pai à busca da lei: o significado da passagem ao ato delinqüente no contexto familiar e institucional. Psicologia: Teoria e Pesquisa, 8(Suplemento), 447-457.

Sudbrack, M. F. O. (1996). Construindo redes sociais: metodologia de prevenção à drogadição e à marginalização de adolescentes de famílias de baixa renda. Em R. M. Macedo (Org.), Família e Comunidade (pp. 87-113). Coletâneas da ANPPEP.

Sudbrack, M. F. O. \& Carreteiro, T. C. O. (2001). Drogas, juventude e complexidade: a ressonância do fenômeno das drogas nas redes sociais de jovens de contextos desfavorecidos e construção de uma metodologia preventiva - estudo em duas capitais brasileiras (Brasília e Rio de Janeiro). Projeto de Auxílio Integrado junto ao $C N P q$ - biênio 2002 - 2004.

Velho, G. (1996). Violência, reciprocidade e desigualdade: Uma perspectiva antropológica. Em G. Velho \& M. Alvito (Orgs.). Cidadania e Violência (pp. 10-24). Rio de Janeiro: UFRJ/FGV.

Volpi, M. (org.) (1999). O adolescente e o ato infracional. São Paulo: Cortez Editora.

Xiberras, M. (1989). La Societé Intoxiquée. Paris: Méridiens Klincksieck.

Zaluar, A \& Leal, M. C. (2001). Violência extra e intramuros. Revista Brasileira de Ciências Sociais, 16(45), 145-164.

Recebido em 29.06.2007

Primeira decisão editorial em 08.10.2007

Versão final em 06.11.2007

Aceito em 04.04.2008 